
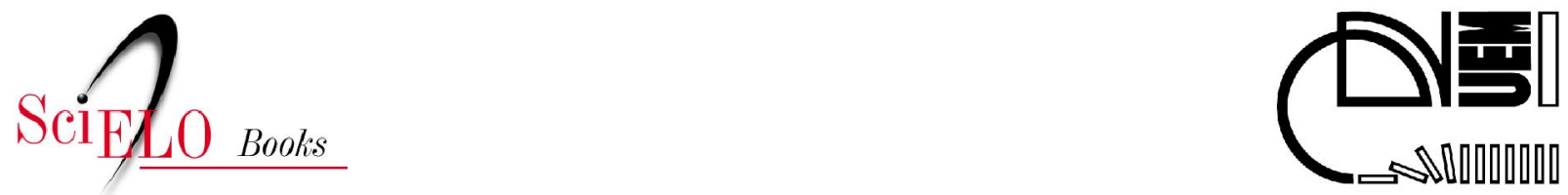

\title{
Chave para gêneros do baixo rio Iguaçu, com categorias superiores
}

\author{
Gilmar Baumgartner \\ Carla Simone Pavanelli \\ Dirceu Baumgartner \\ Alessandro Gasparetto Bifi \\ Tiago Debona \\ Vitor André Frana
}

\section{@(1)(9)}

All the contents of this chapter, except where otherwise noted, is licensed under a Creative Commons Attribution-Non Commercial-ShareAlike 3.0 Unported.

Todo o conteúdo deste capítulo, exceto quando houver ressalva, é publicado sob a licença Creative Commons Atribuição Uso Não Comercial - Partilha nos Mesmos Termos 3.0 Não adaptada.

Todo el contenido de este capítulo, excepto donde se indique lo contrario, está bajo licencia de la licencia Creative Commons Reconocimento-NoComercial-CompartirIgual 3.0 Unported. 


\section{Chave para gêneros do baixo rio Iguaçu, com categorias superiores}
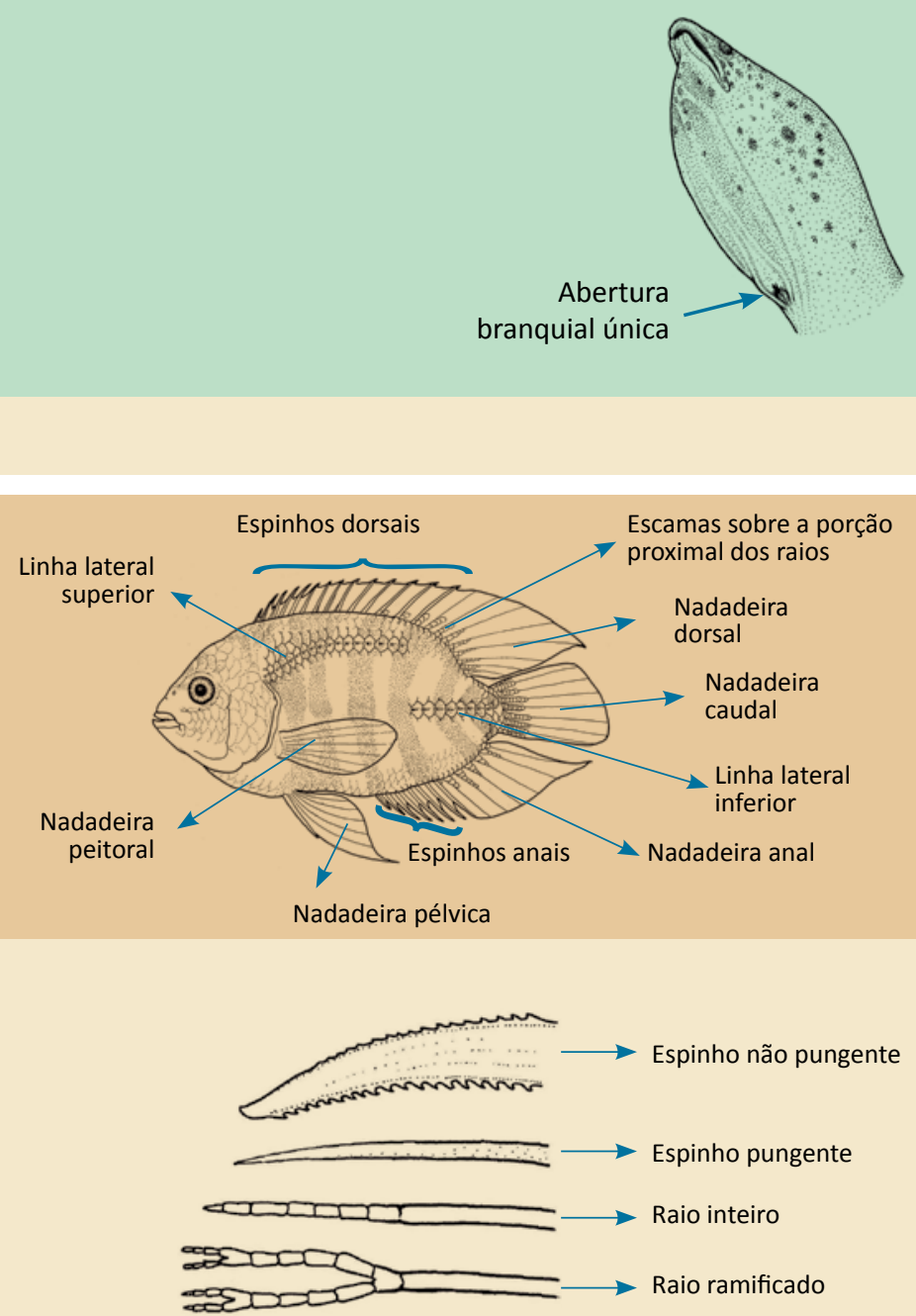
1. Uma única abertura branquial pequena, situada atrás da cabeça, na região mediano-ventral; corpo serpentiforme (SYNBRANCHIFORMES) Synbranchus (Synbranchidae)

1'. Um par de aberturas branquiais; corpo não serpentiforme 2

2. Raios anteriores da nadadeira dorsal e da anal transformados em espinhos pungentes (PERCIFORMES) 3

2'. Nadadeiras dorsal, anal e pélvica, quando presentes, sem espinhos (ou apenas com um dos raios transformado em acúleo, ou parcialmente intumescido, mas não pungente) 

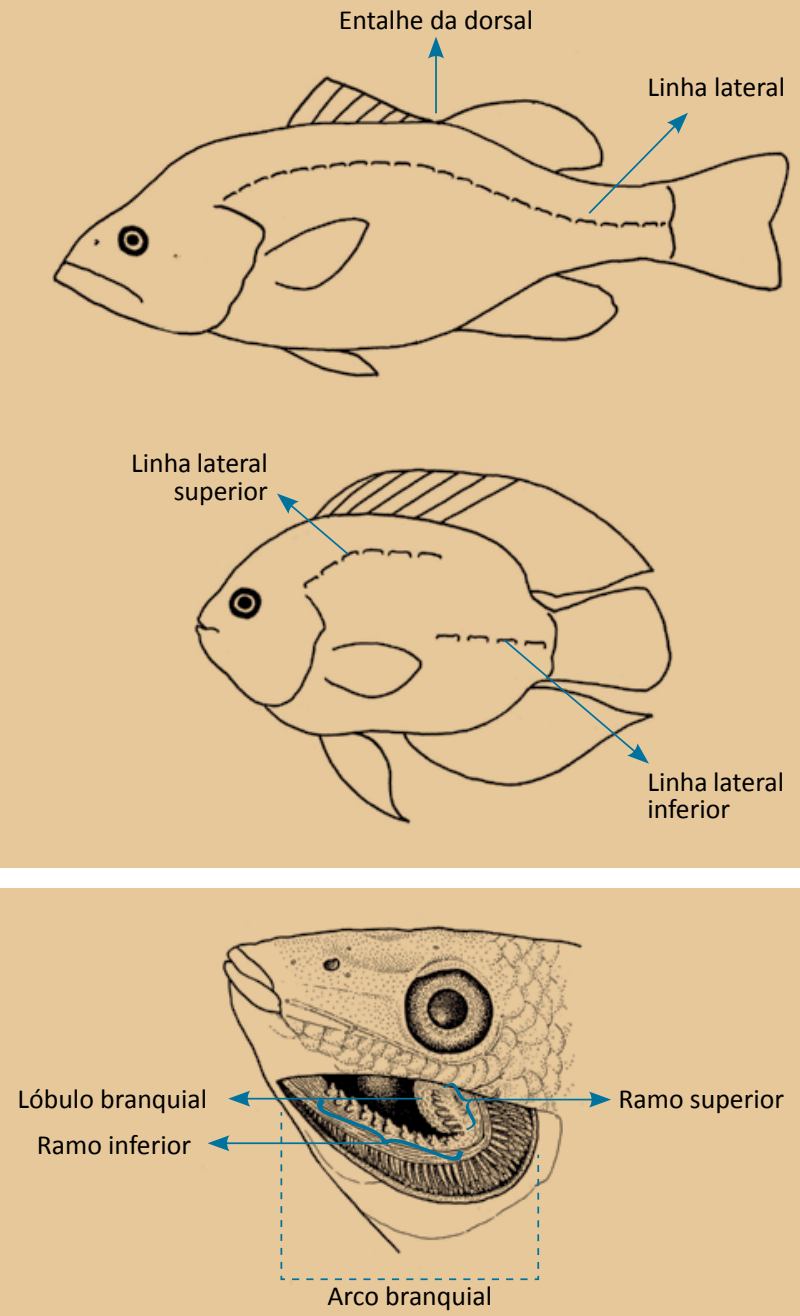
3. Linha lateral ondulada, mas contínua Micropterus (Centrarchidae)

p. 171

3'. Linha lateral interrompida, com um ramo superior e outro inferior

4. Com lóbulo desenvolvido no ramo superior do primeiro arco branquial Geophagus (Cichlidae)

p. 179

4'. Sem lóbulo no primeiro arco branquial 5

5. Escamas pequenas, mais de 65 na linha lateral superior; nadadeira dorsal com entalhe entre a parte de espinhos e a de raios flexíveis Cichla (Cichlidae)

p. 174

5'. Escamas grandes, menos de 30 na linha lateral superior; nadadeira dorsal com margem reta, sem entalhe entre as regiões anterior e posterior 


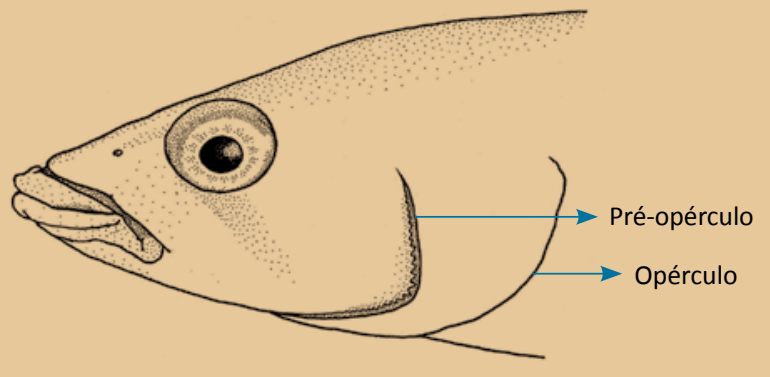


6. Borda posterior do pré-opérculo serrilhada; corpo alongado, sua altura contida 3,5 a 6 vezes no comprimento padrão

Crenicichla (Cichlidae)

p. 176

6'. Borda posterior do pré-opérculo lisa; corpo alto, sua altura contida de 2 a 3 vezes no comprimento padrão

7. Nadadeiras dorsal e anal recobertas por pequenas

escamas sobre a porção proximal dos raios

7'. Nadadeiras dorsal e anal sem escamas; 9

8. Nadadeira anal com mais de 5 raios anteriores transformados em espinho pungente Australoheros (Cichlidae)

8'. Nadadeira anal com no máximo 3 raios anteriores transformados em espinho pungente

9. Nadadeira caudal com várias faixas transversais alternando entre claras e escuras; mais de 20 rastros longos e finos no ramo inferior do primeiro arco branquial Oreochromis (Cichlidae)

p. 180

9'. Nadadeira caudal sem faixas definidas; menos de 15 rastros curtos e grossos no ramo inferior do primeiro arco branquial

Tilapia (Cichlidae)

p. 181 

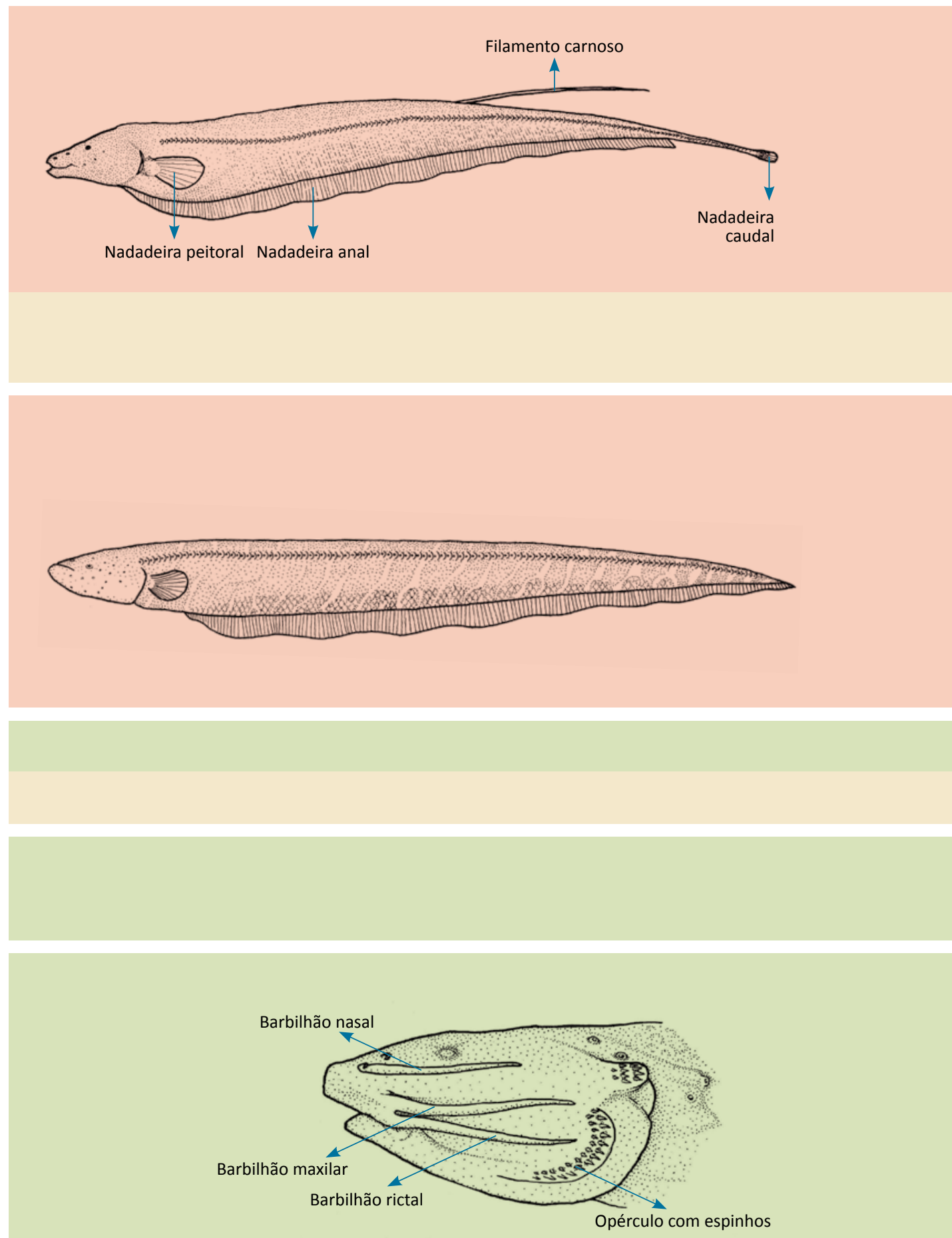
10. Corpo alongado, em forma de faca; nadadeira anal com mais de 100 raios; nadadeiras dorsal e pélvica ausentes (GYMNOTIFORMES)

10'. Corpo nunca em forma de faca; nadadeira anal com menos de 65 raios; nadadeiras dorsal e pélvica presentes

11. Nadadeira caudal presente; boca terminal Apteronotus (Apteronotidae)

p. 151

11'. Nadadeira caudal ausente; boca prognata Gymnotus (Gymnotidae)

12. Corpo nu ou coberto por placas dérmicas (SILURIFORMES) 13

12'. Corpo coberto por escamas 33

13. Corpo totalmente nu, sem placas ósseas 14

13'. Corpo coberto por placas ósseas 24

14. Barbilhões nasais presentes 15

14'. Barbilhões nasais ausentes 17

15. Opérculo com espinhos Trichomycterus (Trichomycteridae) 


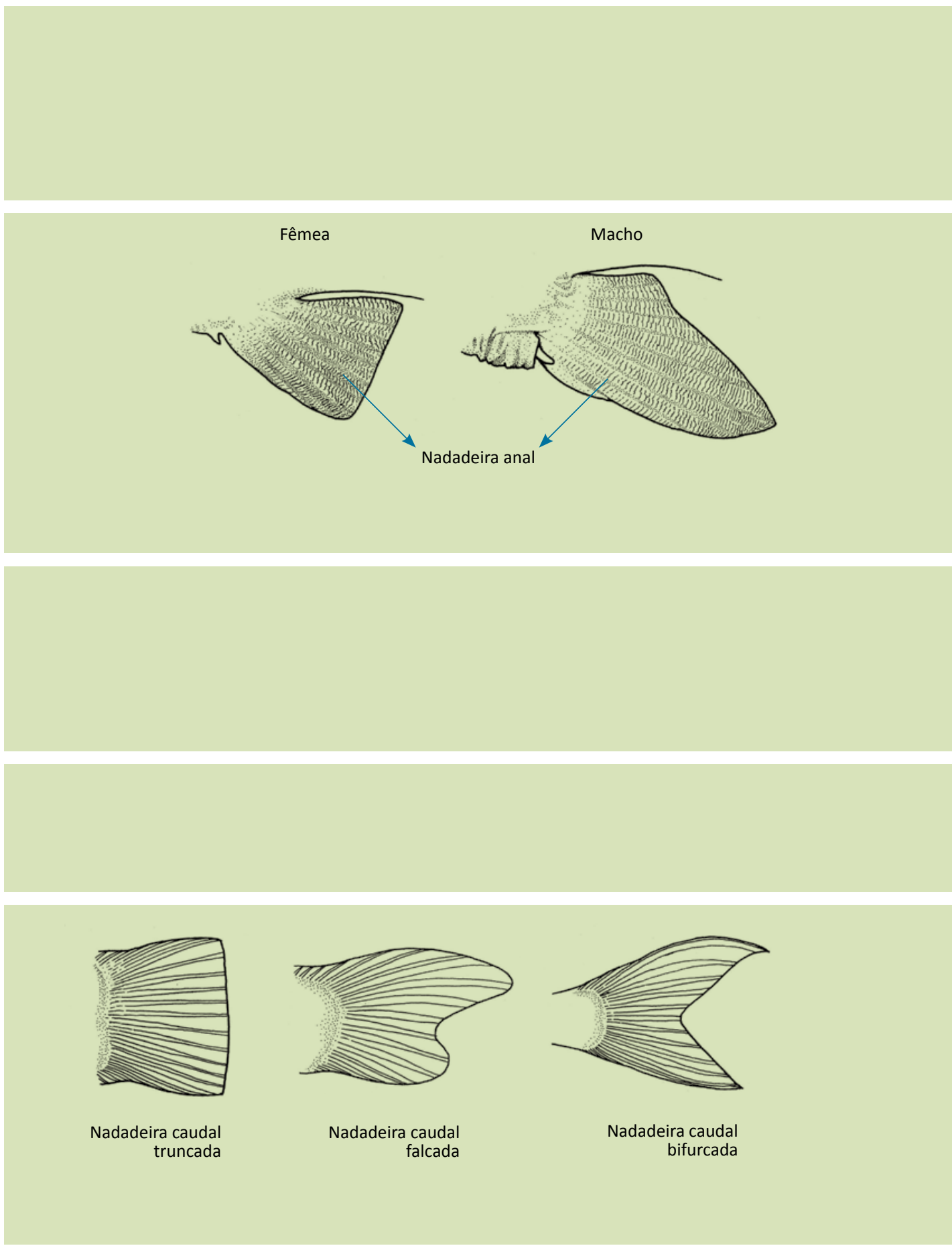


16. Nadadeira anal curta, com menos de 28 raios Ictalurus (Ictaluridae)

16'. Nadadeira anal longa, com mais de 45 raios Clarias (Clariidae)

p. 140

17. Nadadeira adiposa curta, sua base bem menor do que a base da nadadeira anal; machos adultos com dimorfismo sexual na nadadeira anal 18

17'. Nadadeira adiposa longa, sua base bem maior do que a base da nadadeira anal; machos não dimórficos

18. Corpo com coloração de fundo escura, com manchas claras Tatia (Auchenipteridae)

p. 139

18'. Corpo com coloração de fundo clara, com manchas escuras _ Glanidium (Auchenipteridae) p. 138

19. Primeiro raio da nadadeira dorsal não pungente, arredondado 20

19'. Primeiro raio da nadadeira dorsal pungente, perfurante 23

20. Altura do corpo contida mais de 6,5 vezes no comprimento padrão; nadadeira caudal falcada, de borda oblíqua

20'. Altura do corpo contida menos de 5,5 vezes no comprimento padrão; nadadeira caudal bifurcada

21. Nadadeira anal com 16 a 18 raios Heptapterus (Heptapteridae)

p. 132

21'. Nadadeira anal com 10 a 13 raios "Pariolius" (Heptapteridae) 

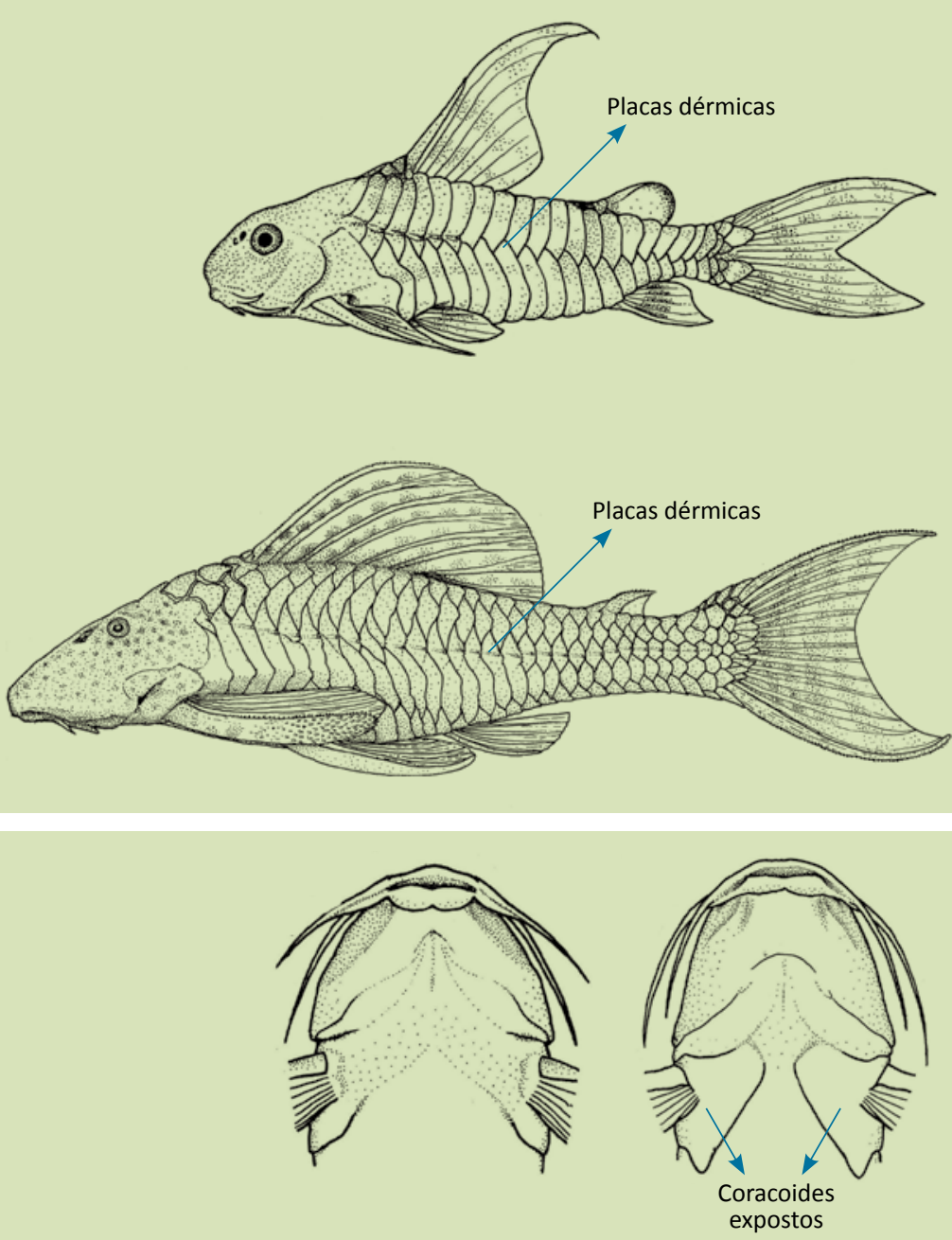

Vista ventral 
22. Nadadeira adiposa longa, sua base contida menos de 3,5 vezes no comprimento padrão Rhamdia (Heptapteridae)

p. 134

22'. Nadadeira adiposa curta, sua base contida mais de 4,5 vezes no comprimento padrão

23. Cabeça não deprimida; olho grande, contido menos de sete vezes no comprimento da cabeça; porte médio Pimelodus (Pimelodidae)

23'. Cabeça muito deprimida; olho pequeno, contido mais de nove vezes no comprimento da cabeça; porte grande

Pseudoplatystoma (Pimelodidae)

24. Duas séries de placas dérmicas altas de cada lado do corpo; boca terminal ou subterminal, não em forma de ventosa 25

24'. Várias séries longitudinais de placas dérmicas de cada lado do corpo; boca inferior, em forma de ventosa

25. Ossos coracoides entre as nadadeiras peitorais cobertos por pele Callichthys (Callichthyidae) 
Pedúnculo caudal deprimido

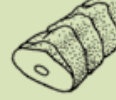

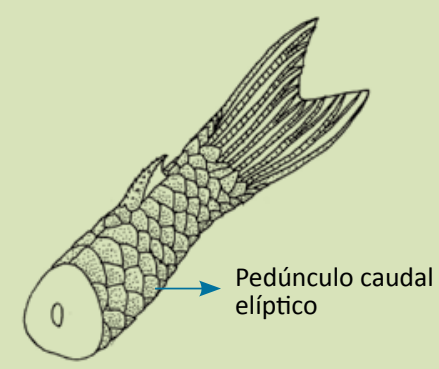
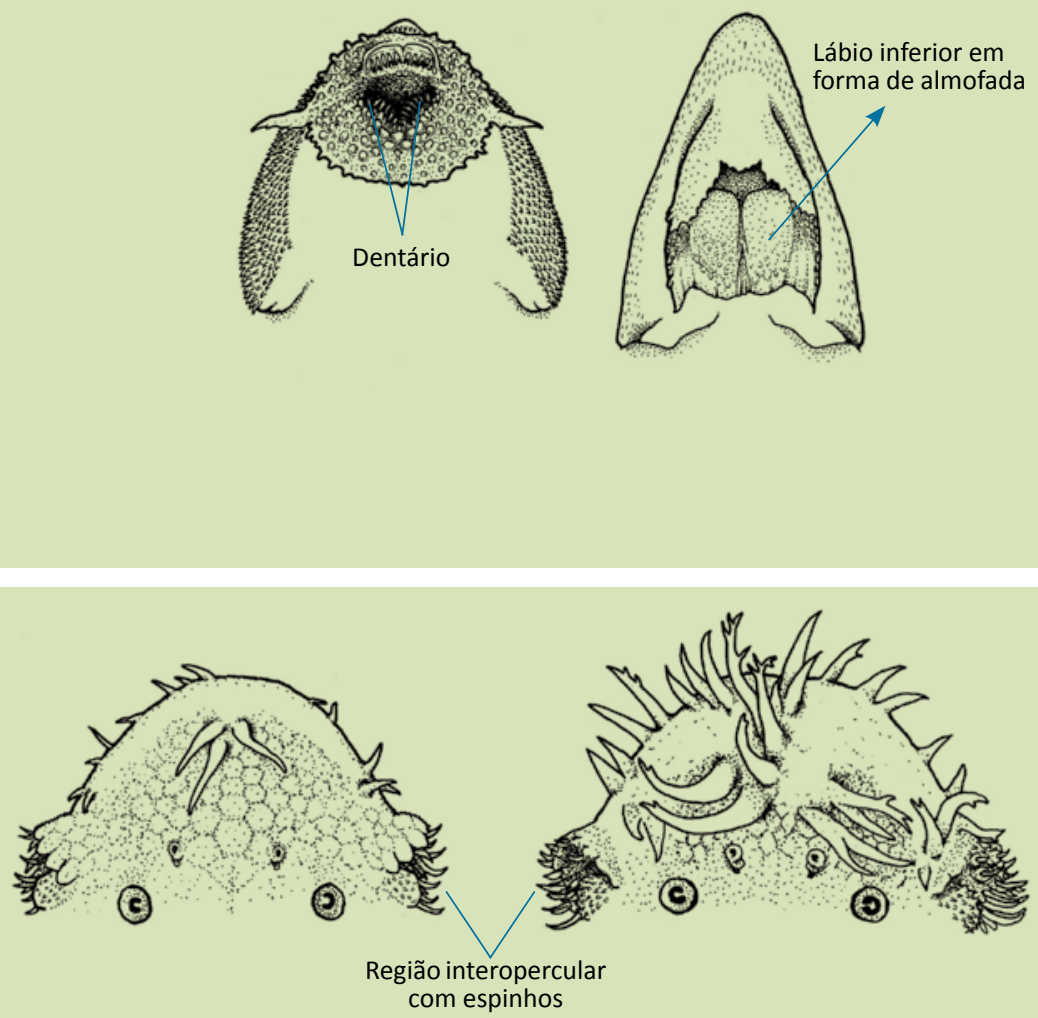
26. Cabeça mais alta do que larga; barbilhões maxilares curtos, não alcançando a abertura branquial Corydoras (Callichthyidae)

26'. Cabeça mais baixa do que larga; barbilhões maxilares longos, ultrapassando a abertura branquial

27. Pedúnculo caudal deprimido, sua altura contida mais de 40 vezes no comprimento padrão; nadadeira adiposa ausente

27'. Pedúnculo caudal elíptico ou arredondado em corte transversal, sua altura contida menos de 20 vezes no comprimento padrão; nadadeira adiposa presente (exceto em Hisonotus)

28. Lábio inferior espesso, em forma de duas almofadas; dentário com 10 a 15 dentes Loricariichthys (Loricariidae)

p. 122

28'. Lábio inferior não almofadado; dentário com 5 a 8 dentes Rineloricaria (Loricariidae)

29. Região interopercular móvel, provida de espinhos longos, fortes e protráteis Ancistrus (Loricariidae) 

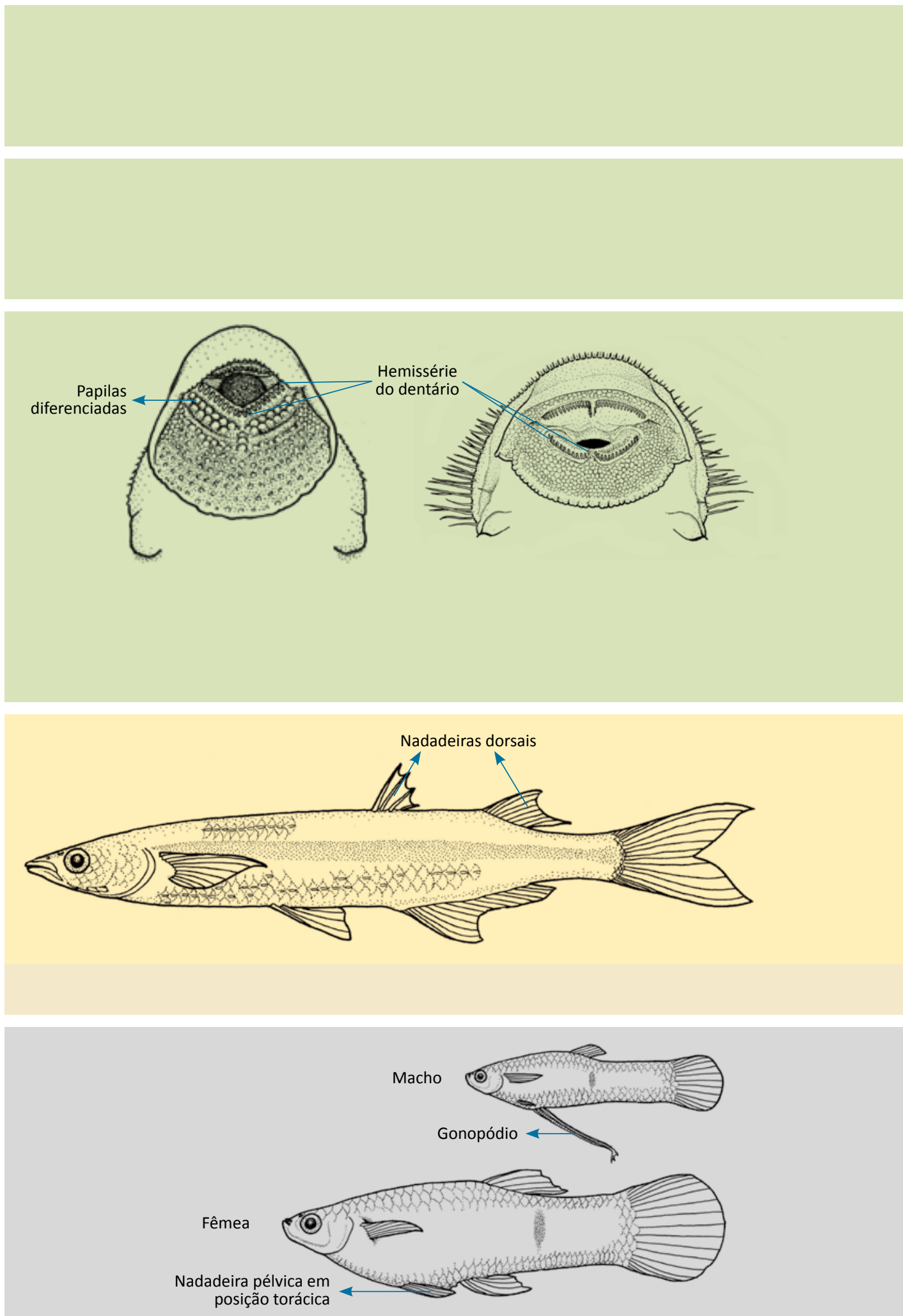
30. Nadadeira adiposa ausente Hisonotus (Loricariidae)

30'. Nadadeira adiposa presente 31

31. Nadadeira anal com cinco raios; porte médio a grande Hypostomus (Loricariidae) p. 128

31'. Nadadeira anal com seis raios; porte pequeno 32

32. Lábio inferior com uma fileira de papilas maiores que as demais, logo atrás dos dentes do dentário; machos sem odontódeos muito desenvolvidos Neoplecostomus (Loricariidae)

p. 118

32'. Lábio inferior sem fileira diferenciada de papilas, sendo todas similares no tamanho; machos adultos com odontódeos muito desenvolvidos na borda do focinho Pareiorhaphis (Loricariidae)

33. Duas nadadeiras dorsais, a primeira com raios espinhosos, mas flexíveis, e a segunda com raios segmentados (ATHERINIFORMES) Odontesthes (Atherinopsidae)

34. Machos adultos com gonopódio; nadadeira pélvica em posição torácica, ou seja, situada sob a peitoral; boca superior (CYPRINODONTIFORMES)

34'. Machos sem gonopódio; nadadeira pélvica em posição abdominal, ou seja, situada atrás da peitoral; boca terminal ou subterminal 
35. Nadadeira dorsal inserida à frente da vertical que passa pela origem da nadadeira anal; corpo com uma faixa longitudinal marrom-escura, às vezes segmentada Jenynsia (Anablepidae)

35'. Nadadeira dorsal inserida atrás da vertical que passa pela

p. 161 origem da nadadeira anal; corpo sem faixa longitudinal

36. Lateral do corpo frequentemente com uma mancha vertical preta, sob a nadadeira dorsal Phalloceros (Poeciliidae)

36'. Lateral do corpo com seis a nove manchas pretas irregulares ao longo do flanco Cnesterodon (Poeciliidae)

37. Maxilas sem dentes 38

37'. Maxilas com dentes, pelo menos parcialmente (CHARACIFORMES, em parte) 42

38. Barbilhão maxilar presente (CYPRINIFORMES) Cyprinus (Cyprinidae)

38'. Barbilhão maxilar ausente 39

39. Mais de 80 escamas na linha lateral Hypophthalmichthys (Cyprinidae)

39'. Menos de 80 escamas na linha lateral 40

40. Nadadeira adiposa ausente Ctenopharyngodon (Cyprinidae)

40'. Nadadeira adiposa presente (CHARACIFORMES, em parte) 41

41. Pedúnculo caudal sem mancha; pequena mancha cinza escuro na nadadeira dorsal, às vezes pouco conspícua; corpo com faixa longitudinal preta e estreita, ao longo de todo o flanco Steindachnerina (Curimatidae)

41'. Pedúnculo caudal com uma mancha cinza-escura grande e conspícua; nadadeira dorsal sem mancha; corpo com faixa longitudinal cinza-escura, larga, mais evidente após a vertical da região de inserção da nadadeira dorsal Cyphocharax (Curimatidae) 

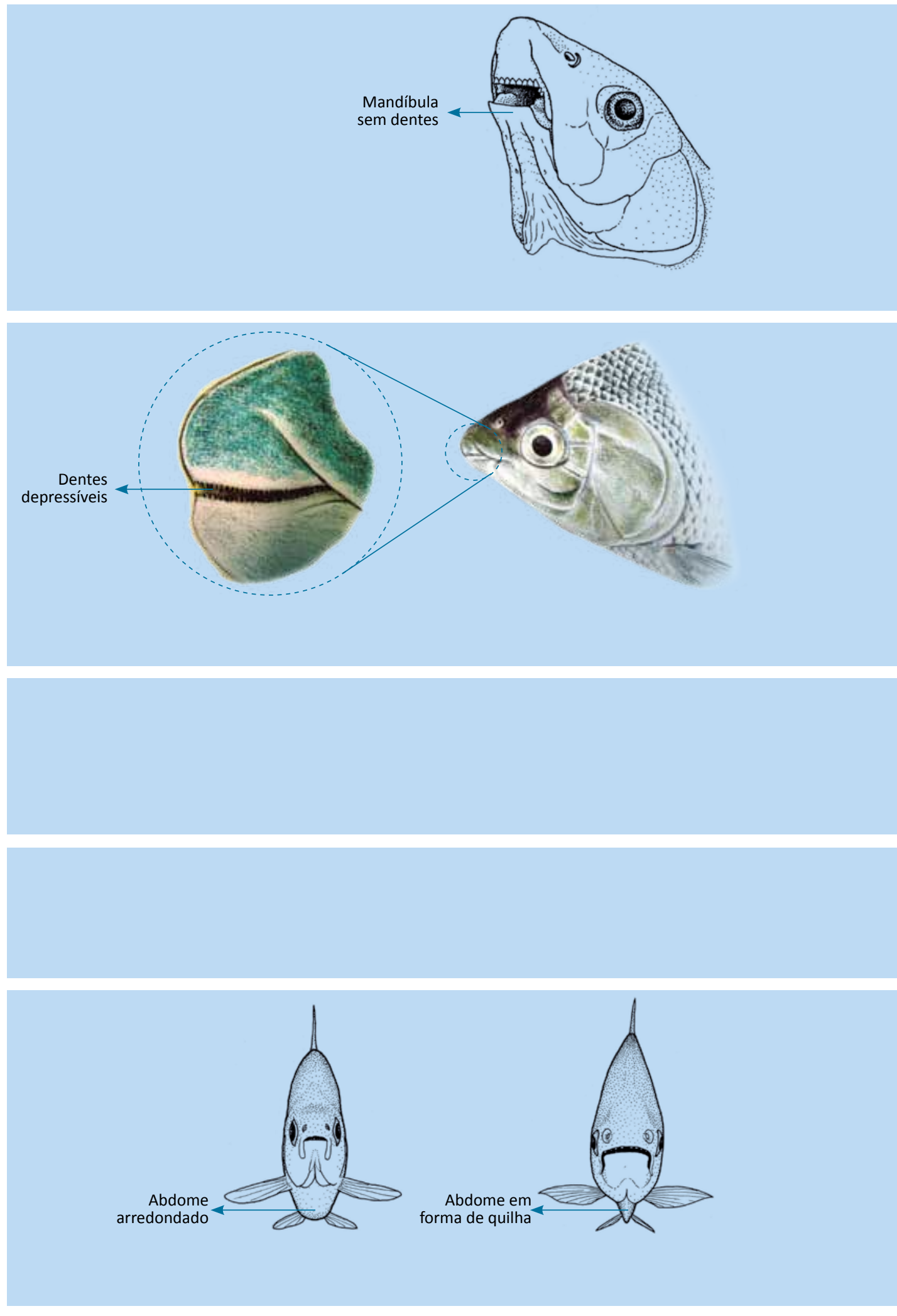
42. Mandíbula sem dentes Apareiodon (Parodontidae)

p. 59

42'. Mandíbula com dentes

43. Dentes depressíveis, pequenos e numerosos, implantados nos lábios

Prochilodus (Prochilodontidae)

43'. Dentes bem desenvolvidos, não depressíveis, implantados nos ossos das maxilas

44. Três, raramente dois, raios não ramificados na nadadeira peitoral Characidium (Crenuchidae)

44'. Um raio não ramificado na nadadeira peitoral 45

45. Nadadeira adiposa ausente Hoplias (Erythrinidae)

45'. Nadadeira adiposa presente p. 98 46

46. Abdome comprimido, em forma de quilha; linha lateral com mais de 100 escamas Piaractus (Serrasalmidae)

46'. Abdome arredondado; linha lateral com menos de 100 escamas 47

47. Uma série de dentes no pré-maxilar 48

47'. Duas ou três séries de dentes no pré-maxilar 49 


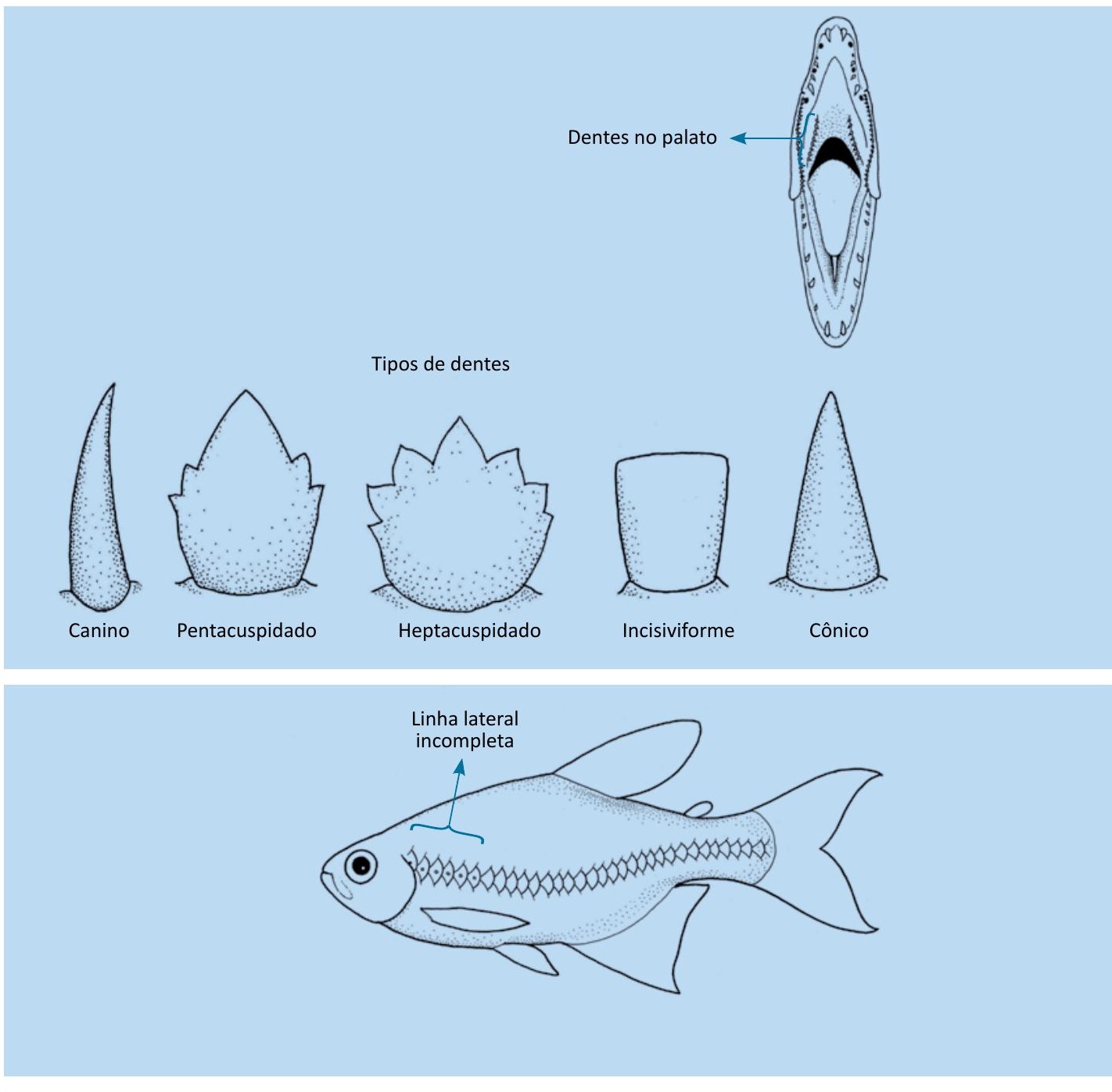


48. Dentes presentes no palato; dentes do pré-maxilar cônicos e numerosos

Oligosarcus (Characidae)

p. 88

48'. Dentes ausentes no palato; dentes do pré-maxilar incisiviformes nos adultos e em número máximo de quatro Leporinus (Anostomidae)

p. 64

49. Linha lateral incompleta 50

49’. Linha lateral completa 51

50. Corpo alto, sua altura contida menos de três vezes no comprimento padrão; colorido do corpo de padrão reticulado, com a borda das escamas escurecida; nadadeira anal curta, com menos de 25 raios; origem da nadadeira dorsal anterior à vertical da origem da nadadeira anal Hyphessobrycon (Characidae)

p. 87

50'. Corpo baixo, sua altura contida mais de três vezes no comprimento padrão; colorido do corpo não reticulado; nadadeira anal longa, com mais de 30 raios; origem da nadadeira dorsal posterior à vertical da origem da nadadeira anal Mimagoniates (Characidae) 
Três séries de dentes no pré-maxilar

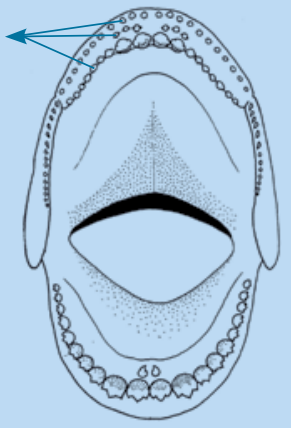

Duas séries de dentes no pré-maxilar

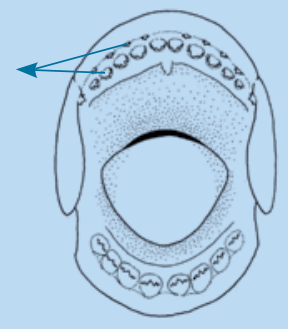


51. Três séries de dentes no pré-maxilar Brycon (Characidae)

p. 91

51'. Duas séries de dentes no pré-maxilar 52

52. Mais de 90 escamas na linha lateral; porte grande Salminus (Characidae)

52'. Menos de 45 escamas na linha lateral; porte pequeno

53. Apenas dentes cônicos ou caninos na maxila superior Gênero indeterminado (Characidae)

\section{p. 86}

53'. Dentes cuspidados na maxila superior 54

54. Quatro dentes na série interna do pré-maxilar; boca subterminal Bryconamericus (Characidae

54.' Quatro ou cinco dentes na série interna do pré-maxilar; boca terminal 55

55. Nadadeira pélvica com oito ou nove (raramente sete) raios; nadadeira dorsal com 11 (raramente 10) raios Astyanax (Characidae)

55'. Nadadeira pélvica com sete raios; nadadeira dorsal com 10 raios Cyanocharax (Characidae) 
